\title{
Editorial
}

\section{The concept of neurosciences in rural practice}

Providing equity of healthcare and research facilities in the field of neurosciences, within underprivileged country and/or countries will help share knowledge and facilities by experts as well as people without financial constraints or their ability to pay. In many remote and rural areas of resource-constrained countries, it is our experience that medical, political, socio-economic and cultural factors can result in treatment gap resulting in less than recommended treatment of many health problems including neurological disorders. There is a need to develop ways to maintain a constant supply of resources, upgrade the infrastructure and dissipate the knowledge without compromising the quality, particularly to the poorest and neediest living in the segregated regions of developing countries at a lowest possible affordability.

It has been described that "rural medicine" opens the opportunity to practice "real" medicine with the challenge to work that can attract the most capable candidates. ${ }^{[1]}$ The primary goal of "Journal of Neurosciences in Rural Practice" is to provide a comprehensive platform to the experts in the field of neurosciences, where practical aspects of the difficulties faced by these consultants and professionals while working in rural and remote areas with limited resources can be put across, discussed and shared with the international intellectual community.
This forum is also intent to provide an opportunity to share the experience, expertise, innovative interventional programs, healthcare modules and policies in the field of neurosciences to reduce the morbidity and mortality especially in the underprivileged particularly in rural areas without added burden to the low-income countries as well to the people also it is anticipated that the benefit would continue in the longer term to serve the mankind with this noble approach.

Amit Agrawal

Department of Neurosurgery, Datta Meghe Institute of Medical Sciences, Sawangi (Meghe), Wardha, India

Address for correspondence: Dr. Amit Agrawal, Department of Neurosurgery, Datta Meghe Institute of Medical Sciences, Sawangi (Meghe), Wardha- 442 005, Maharashtra, India. E-mail: dramitagrawal@gmail.com

DOI: $10.4103 / 0976-3147.63091$

\section{Reference}

1. Glenwood LP. Rural practice: Challenging but endangered? a nova scotia perspective. Can J Rural Med 1996;1:29.

Source of Support: Nil, Conflict of Interest: None declared. 